\title{
Young-Adult Polycystic Kidney Disease is Associated with Major Cardiovascular Complications
}

\author{
Ya-Wen Chuang ${ }^{1,+}$, Tung-Min Yu ${ }^{1,2,+}$, Shih-Ting Huang ${ }^{1}$, Kuo-Ting Sun ${ }^{2,3}$, Ying-Chih Lo ${ }^{1}$, \\ Pin-Kuei Fu ${ }^{4}$, Bor-Jen Lee ${ }^{4}$, Cheng-Hsu Chen ${ }^{1}$, Cheng-Li Lin ${ }^{5,6}$ and Chia-Hung Kao ${ }^{2,7,8, *}$ (iD \\ 1 Division of Nephrology, Taichung Veterans General Hospital, Taichung 40447, Taiwan; \\ colaladr@yahoo.com.tw (Y.-W.C.); yu5523@gmail.com (T.-M.Y.); kitheroborn@hotmail.com (S.-T.H.); \\ neversee@ms41.hinet.net (Y.-C.L.); cschen920@yahoo.com (C.-H.C.) \\ 2 Graduate Institute of Clinical Medical Science and School of Medicine, College of Medicine, \\ China Medical University, Taichung 40447, Taiwan; duke111053@hotmail.com \\ 3 Pediatric Dentistry of Dental Department, China Medical University Hospital, Taichung 40447, Taiwan \\ 4 Department of Critical Care, Taichung Veterans General Hospital, Taichung 40447, Taiwan; \\ yetquen@gmail.com (P.-K.F.); borjen@mail.vghtc.gov.tw (B.-J.L.) \\ 5 Management Office for Health Data, China Medical University Hospital, Taichung 40447, Taiwan; \\ orangechengli@gmail.com \\ 6 College of Medicine, China Medical University, Taichung 40447, Taiwan \\ 7 Department of Nuclear Medicine and PET Center, China Medical University Hospital, \\ Taichung 40447, Taiwan \\ 8 Department of Bioinformatics and Medical Engineering, Asia University, Taichung 40447, Taiwan \\ * Correspondence: d10040@mail.cmuh.org.tw; Tel.: +886-4-2205-2121 (ext. 7412); Fax: +886-4-2233-6174 \\ + Authors equally contributed to this work.
}

Received: 6 April 2018; Accepted: 30 April 2018; Published: 3 May 2018

\begin{abstract}
Background: Patients with polycystic kidney disease (PKD) might have a risk of cardiovascular diseases because several cardiovascular risk factors are occasionally associated with PKD patients. Data on the association between PKD and the risk of cardiovascular events, including acute coronary syndrome (ACS), stroke, and congestive heart failure (CHF), are scant. Methods: Patients aged $\geq 20$ years who were newly diagnosed with PKD (International Classification of Diseases, Ninth Revision, Clinical Modification codes 753.12 and 753.13) between 2000 and 2011 were selected as a PKD cohort $(\mathrm{N}=5157)$. The association between PKD and cardiovascular events was analyzed. Results: We randomly selected a comparison cohort of people without PKD, who were frequency-matched by sex, age, and index date of diagnosis. At the end of 2011, the PKD cohort had a 1.40-fold greater incidence of ACS compared with the comparison cohort ( 8.59 vs. 6.17 per 1000 person-years), in addition to a 1.40-fold greater incidence of stroke, a 1.49-fold greater incidence of CHF, and a 1.64-fold greater incidence of mortality. Conclusions: This retrospective cohort study shows that patients with PKD have an increased risk of cardiovascular events including ACS, stroke, and $\mathrm{CHF}$ as well as mortality, particularly in younger patients. Early identification is necessary to attenuate the risk of cardiovascular complications in patients with PKD.
\end{abstract}

Keywords: polycystic kidney disease; acute coronary syndrome (ACS); stroke; congestive heart failure (CHF); survival

\section{Background}

Polycystic kidney disease (PKD), a multisystem disorder of ciliary proteins, is occasionally complicated by extra-renal manifestations [1]. The most prevalent PKD in adulthood is autosomal dominant PKD (ADPKD), which is also the most common detrimental monogenetic disorder $[1,2]$. 
Although large interfamilial and intrafamilial variations exist in patients with PKD, mutations of the PKD1 (chromosome region 16p13.3, approximately 85\% of cases) and PKD2 (4q21, approximately 15\% of cases) genes account for most PKD cases [2].

Previous study suggested that polycystins are associated with the vascular abnormality of blood vessels [3].

Polycystin 1 (PC1) and polycystin 2 (PC2), the defect proteins in ADPKD, are found in both vascular smooth muscle cells (VSMC) and endothelial cells that are involved in all major vessels including the aorta and intracranial arterials [4-6]. The interactions between PC1/PC2 and VSMCs are complex. Previous data indicated that the dysregulation of $\mathrm{Ca}^{2+}$ homeostasis, which resulted from the mutation of PC1/PC2, may lead to an increase in VSMC proliferation and apoptosis resembling the Pkd-mutant phenotype [7].

Moreover, several lines of studies suggested that the mTOR signaling pathway is involved with patho-physiological changes of VSMCs including proliferation, differentiation, and migration with increased extracellular matrix protein synthesis [8].

VSMCs after injury are frequently prone to abnormal proliferation and matrix synthesis which eventually contributes to intimal hyperplasia and lumen narrowing in vessels [9].

The mTOR pathway inhibitor is shown to be effective in the attenuation of intimal hyperplasia in an animal model and clinical trials $[10,11]$.

There is overwhelming evidence for the hyperactivity of mTOR signaling in PKD [12,13]. Edelstein et al. firstly found that mTOR could involve the progression of cyst changes in the Han: SPRD rat model of PKD [14]. In addition, Shillingford et al. further demonstrated a substantial role of mTOR contributing to the pathogenesis of human PKD and suggested that patients with PKD are likely to be associated with an aberrant activity of mTOR [15].

Accordingly, it is reasonable to suppose that PKD is associated with a higher risk of vascular complications because of the hyperactivity of mTOR resulting from a PC1/2 deficiency.

In patients with PKD, the underlying defect in the connective tissue matrix has been associated with various extrarenal manifestations including intracranial aneurysms, hepatic cysts, diverticulosis, spontaneous coronary artery dissection (SCAD), atrial fibrillation [16], and other cardiovascular abnormalities [17].

However, data regarding the relationship between PKD and the risk of cardiovascular events such as coronary artery disease and cerebral vascular disease remain limited, particularly for acute coronary syndrome (ACS) characterized by unstable angina with a non-ST-segment elevation myocardial infarction and ST-segment elevation myocardial infarction, which is a life-threatening condition $[18,19]$.

In the current study, we used the large claims database of the Taiwan National Health Insurance (NHI) program to conduct a nationwide cohort study to investigate the risk of cardiovascular events, including ACS and stroke, in patients with PKD.

\section{Materials and Methods}

\subsection{Data Source}

The NHI program covers more than $99 \%$ of the population of Taiwan (http:/ / www.nhi.gov.tw / english/index.aspx). The Bureau of National Health Insurance authorized the Taiwan National Health Research Institutes to manage the electronic medical records of patients enrolled in this program and establish the National Health Insurance Research Database (NHIRD) for research purposes. Information available in the database includes the demographic status of insurants; medical diagnoses, treatment procedures, and drug prescriptions for inpatient and outpatient services; and healthcare facilities providing care services to patients. For this study, we used a subset of the NHIRD containing health care data including files of inpatients claims, and the Registry of Beneficiaries. To ensure the privacy of personal information, unique encrypted identification numbers are used for all patients. All claimed data sets can be linked using these anonymous identification numbers. All diagnoses 
were defined using the International Classification of Diseases, Ninth Revision, Clinical Modification (ICD-9-CM).

\subsection{Data Availability Statement}

The dataset used in this study is held by the Taiwan Ministry of Health and Welfare (MOHW). The Ministry of Health and Welfare must approve our application to access this data. Any researcher interested in accessing this dataset can submit an application form to the Ministry of Health and Welfare requesting access. Please contact the staff of MOHW (Email: stcarolwu@mohw.gov.tw) for further assistance. Taiwan Ministry of Health and Welfare Address: No. 488, Sec. 6, Zhongxiao E. Rd., Nangang Dist., Taipei City 115, Taiwan (R.O.C.). Phone: $+886-2-8590-6848$. All relevant data are within the paper.

\subsection{Ethics Statement}

The NHIRD encrypts patient personal information to protect privacy and provides researchers with anonymous identification numbers associated with relevant claims information, including sex, date of birth, medical services received, and prescriptions. Therefore, patient consent is not required to access the NHIRD. This study was approved to fulfill the condition for exemption by the Institutional Review Board (IRB) of China Medical University (CMUH104-REC2-115-CR2). The IRB also specifically waived the consent requirement.

\subsection{Study Patients}

Figure 1 shows the selection process of the participants in the 2 study cohorts. From the inpatient database, we chronologically identified 5721 patients aged $\geq 20$ years who were newly diagnosed with PKD (ICD-9-CM codes 753.12 and 753.13) between 2000 and 2011. The diagnosis date was designated as the "start date" of the follow-up period (in years). For each PKD patient, we randomly selected 4 controls frequency-matched by sex, age, start date, and comorbidities of hypertension (ICD-9-CM codes 401-405), diabetes (ICD-9-CM code 250), chronic obstructive pulmonary disease (COPD; ICD-9-CM codes 491, 492, and 496), chronic kidney disease (CKD; ICD-9-CM code 585), hyperlipidemia (ICD-9-CM code 272), and end-stage renal disease (ESRD; ICD-9-CM code 585 with catastrophic certification). We gave the controls (non-PKD cohort) the same start year as cases (PKD cohort) and then randomly assigned months and days to the controls as the start date of the controls. The study populations in both cohorts were followed from the start dates until the development of ACS or other events of interest, until they were censored for loss to follow-up or withdrawal from the NHI program, or until the end of 2011. The primary goal of this study was to compare the risk of 3 outcomes and mortality between patients with and without PKD: (1) ACS (ICD-9-CM codes 410, 411.1, and 411.8) including unstable angina (ICD-9-CM code 411.1), NSTEMI (ICD-9-CM codes 410.70-410.72), and STEMI (ICD-9-CM codes 410.0-410.9, except for codes 410.70-710.72); (2) stroke (ICD-9-CM codes 430-438) including hemorrhagic stroke (ICD-9-CM codes 430-432) and ischemic stroke (ICD-9-CM codes 433-438); and (3) heart failure (ICD-9-CM code 428) as well as patient death. Patients identified with these disorders were excluded at the baseline. 


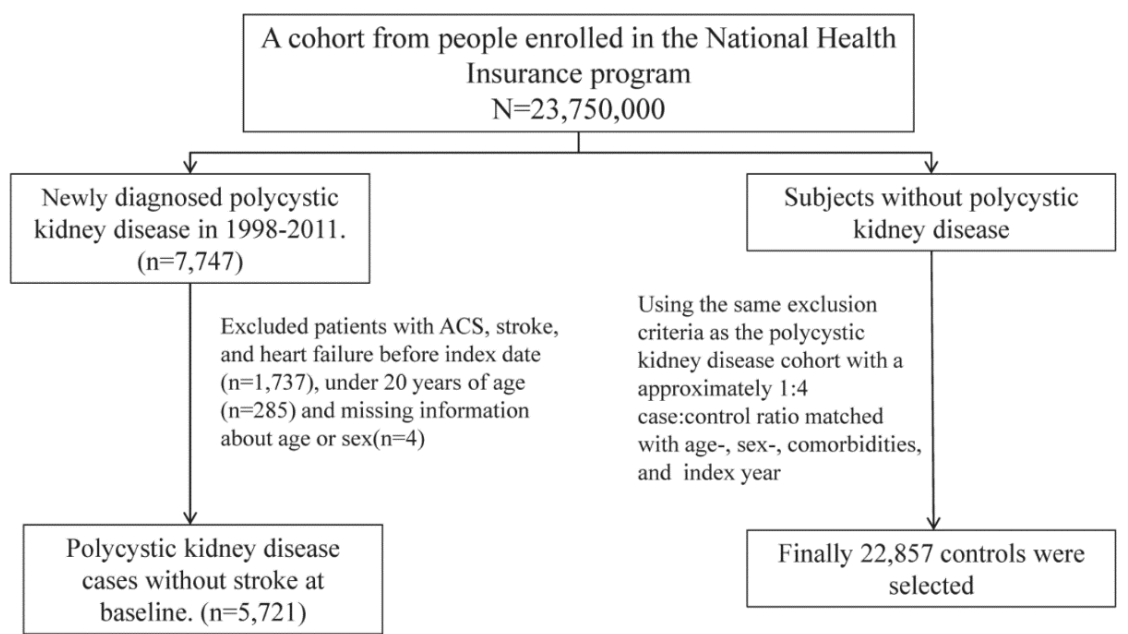

Figure 1. Shows the selection process of the participants in the 2 study cohorts.

\subsection{Statistical Analysis}

Distributions of sex, age (20-49,50-64, and $\geq 65$ years), and comorbidities (yes and no) were compared between the cohorts with and without PKD. We used the Chi-squared test to examine categorical variables and the Wilcoxon rank-sum test to examine the skewed age distributions between the groups. For events significantly associated with PKD, we used the Kaplan-Meier method to calculate and plot the cumulative incidences of such events and examined the differences between the cohorts by using the log-rank test. We also calculated the overall incidence rates of each study event in both cohorts. Because mortality was a critical factor affecting the estimation of ACS, stroke, and heart failure risk, we considered the event of death as a competing event to estimate subhazard ratios (SHRs) and 95\% confidence intervals (CIs) by using the standard univariable and multivariable Cox proportional hazards regression models [20]. Cox regression models were used to calculate the crude hazard ratios (HRs) and 95\% CIs of PKD-related mortality in the PKD and non-PKD cohorts. We also used events with a significant crude SHR (cSHR) or crude HR to calculate the relative adjusted SHR (aSHR) or adjusted HR (aHR) of the events associated with PKD through multivariable Cox regression analysis after controlling the baseline characteristics. The joint effect between PKD and the comorbidities was also measured for outcome events that were significantly associated with PKD. SAS 9.3 statistical software (SAS Institute, Inc., Cary, NC, USA) was used for all statistical analyses. The 2-sided significance level was set at 0.05.

\section{Results}

Table 1 presents the baseline data of the PKD and comparison cohorts; the baseline characteristics were similar in both cohorts. As shown in Figure 2, the cumulative incidence rates of ACS, stroke, congestive heart failure (CHF), and mortality were all greater in the PKD cohort than in the non-PKD cohort.

Table 1. Characteristics of patients between patients with and without polycystic kidney disease (PKD).

\begin{tabular}{|c|c|c|c|c|c|}
\hline \multirow{5}{*}{ Age, Year } & \multicolumn{4}{|c|}{ Polycystic Kidney Disease } & \multirow{4}{*}{$p$-Value } \\
\hline & \multirow{2}{*}{\multicolumn{2}{|c|}{$\begin{array}{c}\text { Yes } \\
(\mathrm{N}=5721)\end{array}$}} & \multirow{2}{*}{\multicolumn{2}{|c|}{$\begin{array}{c}\text { No } \\
(\mathrm{N}=22,857)\end{array}$}} & \\
\hline & & & & & \\
\hline & \multirow[t]{2}{*}{$\mathbf{N}$} & \multirow[t]{2}{*}{$\%$} & $\mathbf{N}$ & $\%$ & \\
\hline & & & & & 0.99 \\
\hline $20-49$ & 2080 & 36.4 & 8308 & 36.4 & \\
\hline $50-64$ & 1676 & 29.3 & 6695 & 29.3 & \\
\hline$\geq 65$ & 1965 & 34.4 & 7854 & 34.4 & \\
\hline Median (IQR) \# & 56.0 & $(45.1-70.3)$ & 56.1 & $(45.1-70.5)$ & 0.76 \\
\hline
\end{tabular}


Table 1. Characteristics of patients between patients with and without polycystic kidney disease (PKD).

\begin{tabular}{|c|c|c|c|c|c|}
\hline \multirow{5}{*}{ Age, Year } & \multicolumn{4}{|c|}{ Polycystic Kidney Disease } & \multirow{4}{*}{$p$-Value } \\
\hline & & & & & \\
\hline & \multicolumn{2}{|c|}{$(\mathrm{N}=5721)$} & \multicolumn{2}{|c|}{$(\mathrm{N}=22,857)$} & \\
\hline & $\mathbf{N}$ & $\%$ & $\mathbf{N}$ & $\%$ & \\
\hline & & & & & 0.99 \\
\hline Gender & & & & & 0.98 \\
\hline Female & 2250 & 44.6 & 10,192 & 44.6 & \\
\hline Male & 3171 & 55.4 & 12,665 & 55.4 & \\
\hline \multicolumn{6}{|l|}{ Comorbidity } \\
\hline Hypertension & 2504 & 43.8 & 10,006 & 43.8 & 0.99 \\
\hline Diabetes & 610 & 10.7 & 2432 & 10.6 & 0.96 \\
\hline Hyperlipidemia & 236 & 4.13 & 933 & 4.08 & 0.88 \\
\hline COPD & 327 & 5.72 & 1293 & 5.66 & 0.86 \\
\hline Chronic kidney disease & 1234 & 21.6 & 4915 & 21.5 & 0.91 \\
\hline ESRD & 564 & 9.86 & 2239 & 9.80 & 0.89 \\
\hline
\end{tabular}

Chi-square test; " Wilcoxon signed rank test. IQR: interquartile range. COPD: chronic obstructive pulmonary disease. ESRD: end-stage renal disease.
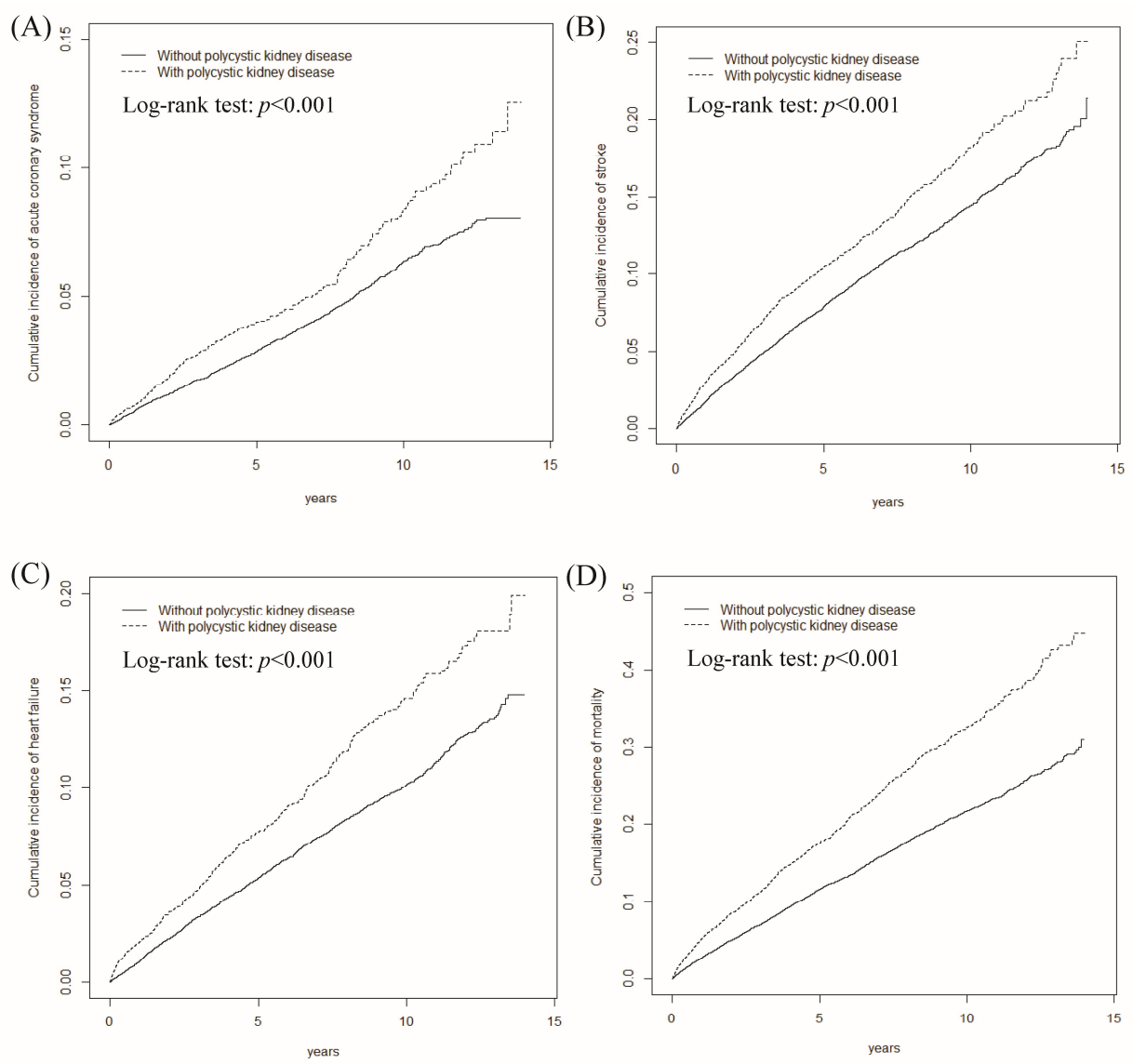

Figure 2. Cumulative incidence of acute coronary syndrome (A); stroke (B); congestive heart failure (C); and mortality (D) for polycystic kidney disease cohort (dashed line) and comparison cohort (solid line).

Table 2 shows the overall incidence rates of the 3 events between the PKD and non-PKD cohorts as well as the cSHRs of the events in these cohorts. The PKD patients were at a higher risk of all events than the comparisons. Overall, comparing the PKD and non-PKD cohorts revealed that the PKD cohort had a higher incidence of ACS (8.59 vs. 6.17 per 1000 person-years), unstable angina (1.98 vs. 1.26 per 1000 person-years), stroke (21.5 vs. 16.1 per 1000 person-years), hemorrhagic stroke (6.16 vs. 2.97 per 1000 person-years), ischemic stroke (15.3 vs. 13.2 per 1000 person-years), and CHF (16.3 vs. 
11.1 per 1000 person-years), corresponding to cSHR values of $1.40(95 \% \mathrm{CI}=1.22-1.61), 1.41$ (95\% $\mathrm{CI}=1.05-1.89), 1.40(95 \% \mathrm{CI}=1.28-1.53), 2.12(95 \% \mathrm{CI}=1.78-2.53), 1.20(95 \% \mathrm{CI}=1.08-1.33)$, and 1.49 $(95 \% \mathrm{CI}=1.34-1.65)$, respectively. The sex-specific PKD-to-non-PKD cohort relative risk of ACS was significant for men ( $\mathrm{cSHR}=1.47,95 \% \mathrm{CI}=1.24-1.74)$. Furthermore, the age-specific PKD-to-non-PKD relative risk of ACS was high for all age groups. Notably, in the group aged 20-49 year-old, a 1.61-fold increased risk of ACS $(95 \% \mathrm{CI}=1.18,2.21), 1.65$-fold in stroke $(95 \% \mathrm{CI}=1.32,2.07)$, and 1.82 -fold in CHF $(95 \% \mathrm{CI}=1.37,2.42)$ was noted.

Table 2. Incidence and hazard ratio of outcome between patients with and without polycystic kidney disease.

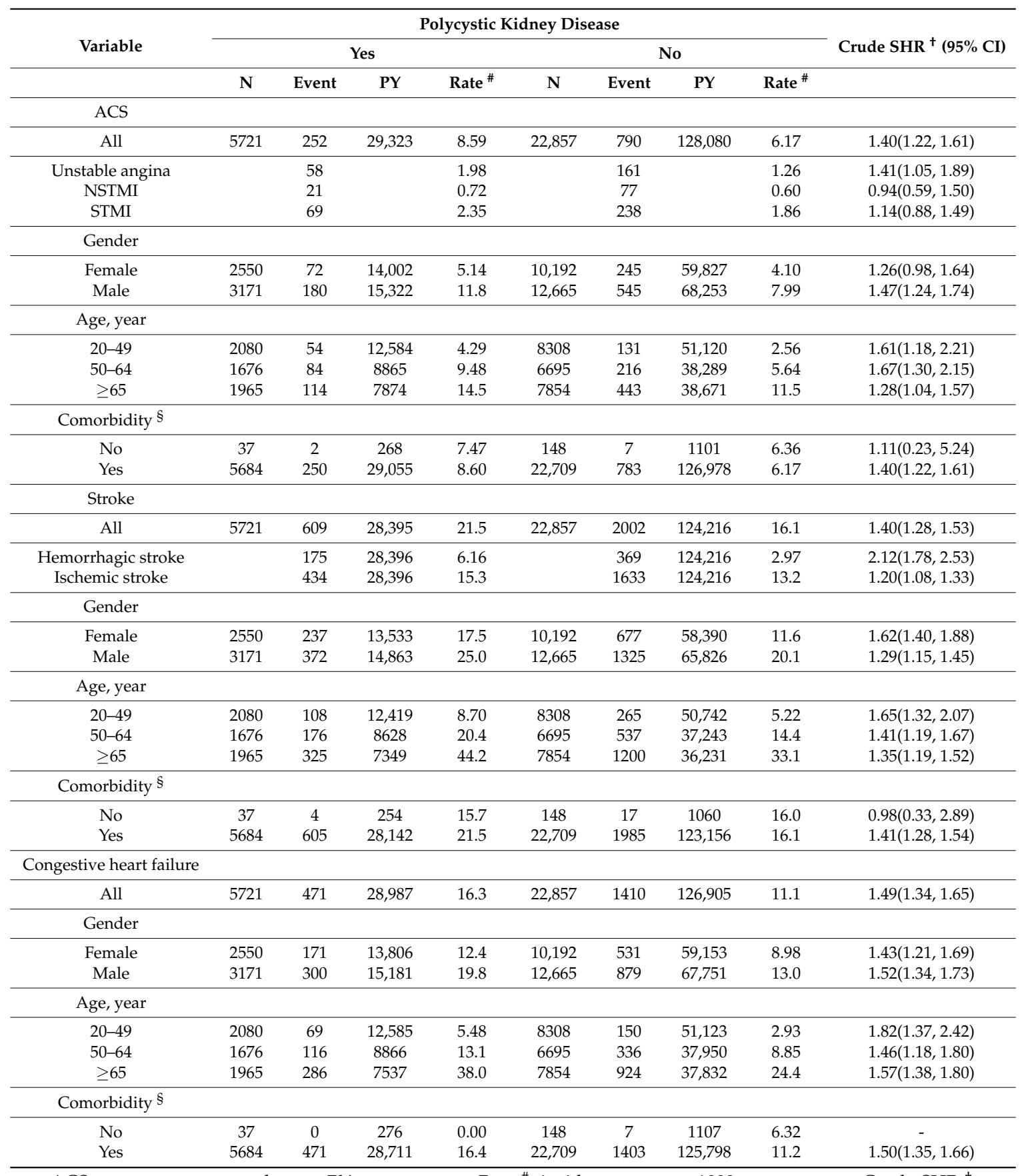

ACS, acute coronary syndrome. PY, person-years; Rate ${ }^{\#}$, incidence rate per 1000 person-years. Crude SHR ${ }^{\dagger}$, relative hazard ratio. Comorbidity \$: Patients with any one of the comorbidities (including hypertension, diabetes, hyperlipidemia, COPD, chronic kidney disease and ESRD) were classified as the comorbidity group. NSTMI: non-ST elevation myocardial infarction. STMI: ST elevation myocardial infarction. 
PKD patients with comorbidities were associated with significantly higher risks of ACS than the non-PKD patients. The PKD cohort was 1.40-fold more likely to develop stroke (95\% CI $=1.28-1.53)$, 2.12-fold more likely to develop hemorrhagic stroke ( $95 \% \mathrm{CI}=1.78-2.53)$, and 1.20-fold more likely to develop ischemic stroke ( $95 \% \mathrm{CI}=1.08-1.33)$ compared with the non-PKD cohort. We compared the risks of stroke and CHF between the PKD and non-PKD cohorts in terms of several variables including sex, age, and the presence or absence of comorbidities. In all stratifications, the risks of stroke and CHF in the PKD cohort were higher than those in the non-PKD cohort, except for patients without comorbidities.

Table 3 shows a significantly high risk of mortality in patients with PKD compared to that in patients without PKD which reached a 1.64-fold increase $(95 \% \mathrm{CI}=1.53-1.75)$. In stratification with sex and age shows that the sex-specific PKD-to-non-PKD cohort relative risk of mortality was significant for men ( $\mathrm{cHR}=1.60,95 \% \mathrm{CI}=1.47-1.73)$ as well as that in women ( $\mathrm{cHR}=1.75,95 \% \mathrm{CI}=1.57-1.97)$. Furthermore, the age-specific PKD-to-non-PKD relative risk of mortality was high for all age groups. Notably, in the group aged 20-49 year-old, a 1.84-fold increased risk of mortality ( $95 \% \mathrm{CI}=1.55,2.18)$.

Table 3. Incidence and hazard ratio of mortality between patients with and without polycystic kidney disease.

\begin{tabular}{|c|c|c|c|c|c|c|c|c|c|}
\hline \multirow{3}{*}{ Variable } & \multicolumn{8}{|c|}{ Polycystic Kidney Disease } & \multirow{3}{*}{$\begin{array}{c}\text { Crude HR }{ }^{\dagger} \\
(95 \% \text { CI })\end{array}$} \\
\hline & \multicolumn{4}{|c|}{ Yes } & \multicolumn{4}{|c|}{ No } & \\
\hline & $\mathbf{N}$ & Event & PY & Rate $^{\#}$ & $\mathbf{N}$ & Event & PY & Rate $^{\#}$ & \\
\hline All & 5721 & 1217 & 30,045 & 40.5 & 22,857 & 3218 & 130,270 & 24.7 & $1.64(1.53,1.75)$ \\
\hline \multicolumn{10}{|l|}{ Gender } \\
\hline Female & 2550 & 416 & 14,224 & 29.3 & 10,192 & 1012 & 60,548 & 16.7 & $1.75(1.57,1.97)$ \\
\hline Male & 3171 & 801 & 15,822 & 50.6 & 12,665 & 2206 & 69,721 & 31.6 & $1.60(1.47,1.73)$ \\
\hline \multicolumn{10}{|l|}{ Age, year } \\
\hline $20-49$ & 2080 & 191 & 12,778 & 15.0 & 8308 & 421 & 51,648 & 8.15 & $1.84(1.55,2.18)$ \\
\hline $50-64$ & 1676 & 347 & 9154 & 37.9 & 6695 & 875 & 38,931 & 22.5 & $1.69(1.50,1.92)$ \\
\hline$\geq 65$ & 1965 & 679 & 8113 & 83.7 & 7854 & 1922 & 39,690 & 48.4 & $1.73(1.59,1.89)$ \\
\hline \multicolumn{10}{|c|}{ Comorbidity $\$$} \\
\hline No & 37 & 7 & 276 & 25.3 & 148 & 13 & 1122 & 11.6 & $2.14(0.86,5.38)$ \\
\hline Yes & 5684 & 1210 & 29,769 & 40.7 & 22,709 & 3205 & 129,148 & 24.8 & $1.64(1.53,1.75)$ \\
\hline
\end{tabular}

Table 4 presents the calculated cSHRs and aSHRs of the 3 PKD-related events and cHRs and aHRs of the mortality after adjustment for sex, age, and baseline comorbidities. Men were at higher risks of ACS, stroke and mortality than women. The hazard of heart failure was higher for patients aged 50-64 years than for those aged 20-49 years. Hypertension, diabetes, CKD, and ESRD were associated with increased risks of ACS, stroke, CHF, and mortality. 
Table 4. Hazard ratios of outcome in association with gender, age and comorbidities in univariable and multivariable competing risk models.

\begin{tabular}{|c|c|c|c|c|c|c|c|c|}
\hline \multirow{2}{*}{ Variable } & \multicolumn{2}{|c|}{ ACS } & \multicolumn{2}{|c|}{ Stroke } & \multicolumn{2}{|c|}{ Congestive Heart Failure } & \multicolumn{2}{|c|}{ Mortality } \\
\hline & $\begin{array}{l}\text { Crude SHR }{ }^{\dagger} \\
(95 \% \text { CI })\end{array}$ & $\begin{array}{c}\text { Adjusted SHR } \ddagger \\
(95 \% \text { CI })\end{array}$ & $\begin{array}{l}\text { Crude SHR }{ }^{\dagger} \\
(95 \% \mathrm{CI})\end{array}$ & $\begin{array}{c}\text { Adjusted SHR } \\
(95 \% \text { CI })\end{array}$ & $\begin{array}{c}\text { Crude SHR }^{\dagger} \\
(95 \% \mathrm{CI})\end{array}$ & $\begin{array}{c}\text { Adjusted SHR } \\
(95 \% \text { CI })\end{array}$ & $\begin{array}{c}\text { Crude HR }{ }^{\dagger} \\
(95 \% \mathrm{CI})\end{array}$ & $\begin{array}{l}\text { Adjusted HR } \\
\quad(95 \% \mathrm{CI})\end{array}$ \\
\hline PKD & $1.40(1.22,1.61)$ & $1.40(1.22,1.62)$ & $1.40(1.28,1.53)$ & $1.39(1.27,1.52)$ & $1.49(1.34,1.65)$ & $1.51(1.36,1.68)$ & $1.64(1.53,1.75)$ & $1.71(1.60,1.83)$ \\
\hline $\begin{array}{l}\text { Gender (Men vs. } \\
\text { women) }\end{array}$ & $1.58(1.39,1.79)$ & $1.55(1.36,1.77)$ & $1.30(1.20,1.40)$ & $1.27(1.17,1.38)$ & $1.07(0.98,1.17)$ & $1.03(0.94,1.13)$ & $1.84(1.73,1.96)$ & $1.42(1.33,1.51)$ \\
\hline \multicolumn{9}{|l|}{ Age, years } \\
\hline $20-49$ & 1(Reference) & 1(Reference) & 1(Reference) & 1(Reference) & 1(Reference) & 1(Reference) & 1(Reference) & 1(Reference) \\
\hline $50-64$ & $1.37(1.03,1.82)$ & $1.19(0.89,1.59)$ & $1.28(1.04,1.57)$ & $1.04(0.84,1.28)$ & $1.79(1.40,2.29)$ & $1.45(1.13,1.84)$ & $2.69(2.44,2.96)$ & $2.32(2.11,2.56)$ \\
\hline$\geq 65$ & $1.23(0.99,1.54)$ & $1.08(0.87,1.35)$ & $1.25(1.07,1.46)$ & $1.12(0.96,1.30)$ & $1.31(1.08,1.58)$ & $1.10(0.91,1.33)$ & $5.78(5.29,6.32)$ & $5.16(4.72,5.65)$ \\
\hline \multicolumn{9}{|l|}{$\begin{array}{c}\text { Baseline } \\
\text { comorbidities } \\
\text { (yes vs. no) }\end{array}$} \\
\hline Hypertension & $1.96(1.74,2.21)$ & $1.76(1.55,1.99)$ & $1.61(1.49,1.74)$ & $1.51(1.39,1.63)$ & $1.69(1.54,1.85)$ & $1.53(1.39,1.68)$ & $1.69(1.59,1.79)$ & $1.21(1.14,1.28)$ \\
\hline Diabetes & $2.21(1.90,2.57)$ & $1.87(1.60,2.18)$ & $1.79(1.62,1.98)$ & $1.65(1.48,1.83)$ & $2.20(1.97,2.45)$ & $2.00(1.78,2.24)$ & $2.07(1.92,2.24)$ & $1.67(1.54,1.81)$ \\
\hline Hyperlipidemia & $2.40(1.95,2.95)$ & $1.87((1.51,2.32)$ & $1.41(1.20,1.67)$ & $1.12(0.95,1.33)$ & $1.69(1.41,2.02)$ & $1.33(1.10,1.59)$ & $1.07(0.93,1.24)$ & $0.88(0.76,1.02)$ \\
\hline COPD & $1.37(1.10,1.70)$ & $1.16(0.93,1.44)$ & $1.42(1.25,1.61)$ & $1.30(1.14,1.48)$ & $1.72(1.50,1.98)$ & $1.52(1.32,1.76)$ & $2.76(2.51,3.03)$ & $1.60(1.45,1.76)$ \\
\hline CKD & $2.20(1.94,2.49)$ & $1.90(1.65,2.20)$ & $1.73(1.60,1.89)$ & $1.64(1.49,1.81)$ & $2.52(2.30,2.76)$ & $2.37(2.14,2.63)$ & $3.36(3.17,3.56)$ & $2.76(2.58,2.95)$ \\
\hline ESRD & $2.12(1.78,2.52)$ & $1.32(1.07,1.61)$ & $1.52(1.33,1.73)$ & $1.03(0.89,1.20)$ & $2.19(1.92,2.50)$ & $1.29(1.11,1.50)$ & $2.80(2.60,3.02)$ & $1.60(1.47,1.74)$ \\
\hline
\end{tabular}

Crude SHR ${ }^{\dagger}$, relative subhazard ratio; Crude $\mathrm{HR}^{\dagger}$, relative hazard ratio; Adjusted SHR $\ddagger$ and Adjusted HR $\ddagger$ : multivariable analysis including gender, age, and comorbidities of hypertension, diabetes, hyperlipidemia, COPD, chronic kidney disease (CKD), and ESRD. 


\section{Discussion}

In this large population-based cohort study with a long observation period of 27,053 person-years, we noted that PKD patients had a significantly higher risk of ACS as well as CHF when compared with non-PKD patients after adjustment for age, sex, and the associated cardiovascular risk factors included hypertension, diabetes, hyperlipidemia, COPD, and CKD. We also found greater risks of stroke and mortality for the PKD cohort than for the non-PKD cohort. Interestingly, our findings disclosed a significantly increased risk of cardiovascular events including ACS, stroke, and CHF in young patients with PKD, which has never been reported previously for such a relatively young age group.

Cardiovascular complications have surpassed infections among the most common causes of morbidity and mortality in patients with PKD $[18,19]$. Some cardiovascular risk factors have been suggested to be closely associated with PKD. Hypertension and left ventricular hypertrophy are commonly observed in patients with PKD [19,21]. Early vascular changes have been reported in young patients with normal blood pressure, and patients with PKD are considered to have a higher prevalence of coronary aneurysm (CA) and cardiac valvular abnormalities than the general population does [19]. Nevertheless, diagnosing SCAD is extremely challenging. Even in patients with a strong clinical suspicion, SCAD is difficult to diagnose accurately by using coronary angiography [22]. Previous studies on SCAD associated with PKD are limited to a few case reports and a study with a small sample size [23-25].

In the present study, after adjusting for associated risk factors including hypertension, diabetes, hyperlipidemia, and chronic kidney disease, multivariate analysis revealed a relatively high hazard of ACS as well as stroke in patients with PKD compared with non-PKD patients. Notably, the age-specific risk of ACS was significantly higher for those who were younger, aged $20-49$ years (HR $=1.61,95 \%$ $\mathrm{CI}=1.18-2.21$ ), and additionally a 1.82 -fold increased risk of CHF was observed in young people with PKD. In addition, the trend is consistent in that a 1.65-fold increased risk of stroke was observed.

More recently, a study on PKD patients indicated that a high prevalence of young-onset hypertension was observed in children with PKD and that may partly support the findings in the present study.

In terms of stratification without co-morbidity, our results showed that the risk of CVD was comparable between patients with and without PKD. The findings may suggest that the associated cardiovascular co-morbidity may contribute more greatly in patients once they have PKD.

Taken together, our findings indicate a higher risk of cardiovascular events in younger patients with PKD that was never previously known.

Previous studies have shown that polycystins are constitutional in normal adult smooth muscle cells $[5,6]$. Polycystins may play an essential role in maintaining the vascular integrity of the myoelastic structure of the arterial wall [26]. An animal study showed that the null mutation of the PKD1 or PKD2 gene could diffuse vascular rupture and hemorrhage in the vessel tissue, suggesting that polycystins have a role in maintaining vascular integrity $[5,27]$. Hence, polycystin deficiency is suggested to be directly attributed to the various phenotypes of vascular abnormality in patients with ADPKD, which are independent of the effect of hypertension [6].

Moreover, accumulating evidence indicates that PKD is likely associated with aberrant mTOR activity. Previous study demonstrated that the cytoplasmic tail of PC1 could inhibit mTOR and the loss function of PC1 in ADPKD would eventually lead to a remarkable hyperactivity of mTOR [13,15].

We previously demonstrated that PKD is significantly associated with the risk of cancer, within which mTOR may play an important role [28]. Whether mTOR has a similar role within it needs further elucidation.

Our study results may provide clinical evidence relevant to previous biological evidence.

Previous study has suggested that a rennin-angiotensin blockade was likely associated with a favorable outcome in PKD patients. Therefore, in terms of cardiovascular complications, it should be firstly considered in PKD patients. Certain limitations of the present study should be considered. First, some data on tobacco smoking and kidney function as glomerular filtration rate are relevant 
to the risk of ACS but are not provided in the NHIRD. Therefore, we included the confounder of COPD, chronic kidney disease, and end stage renal disease (ESRD) in the multivariable analysis to correct any possible bias. Second, we could not obtain details regarding CA and SCAD. The clinical diagnosis of SCAD is challenging and relies completely on visualizing a radiolucent intimal "flap" in coronary angiography [22,29]. In practice, delineating the coronary wall through ordinary cardiac angiography is difficult, limiting its diagnostic accuracy $[22,29,30]$. Nevertheless, the diagnoses of ACS and AMI in the study were not biased by this condition. Third, we did not consider the effects of medications including antihypertensive, antiplatelet, and antidiabetic drugs. This may have led to an underestimation of the risk of ACS in the study. Finally, we could not analyze biological data obtained through genetic analysis including the mutations of the PKD1 and PKD2 genes. We could not examine the individual risks of vascular phenotypes in the study cohort, although this is not necessary for the contemporary diagnosis of PKD or ADPKD.

\section{Conclusions}

Our study reports for the first time that patients with PKD are at increased risk of ACS as well as other cardiovascular events including stroke, $\mathrm{CHF}$, and mortality.

Most important of all, our findings show that young adult PKD is significantly associated with a higher risk of cardiovascular disease when compared with non-PKD patients. The relatively high risk of cardiovascular events such as stroke and heart failure, as well as mortality, should not be ignored in young patients with PKD, and early recognition of the cardiovascular risk in such patients is required.

Author Contributions: Conceptualization: Y.-W.C., C.-H.K. Methodology: C.-L.L., C.-H.K. Software: C.-L.L., C.-H.K. Validation: Y.-W.C., T.-M.Y., C.-H.C., K.-T.S., Y.-C.L., S.-T.H., P.-K.F., B.-J.L., C.-L.L., C.-H.K. Formal analysis: Y.-W.C., T.-M.Y., C.-H.C., K.-T.S., Y.-C.L., S.-T.H., P.-K.F., B.-J.L., C.-L.L., C.-H.K. Investigation: Y.-W.C., C.-H.K. Resources: Y.-W.C., C.-H.K. Data curation: Y.-W.C., T.-M.Y., C.-H.C., K.-T.S., Y.-C.L., S.-T.H., P.-K.F., B.-J.L., C.-L.L., C.-H.K. Writing (original draft preparation): Y.-W.C., T.-M.Y., C.-H.C., K.-T.S., Y.-C.L., S.-T.H., P.-K.F., B.-J.L., C.-L.L., C.-H.K. Writing (review and editing): Y.-W.C., T.-M.Y., C.-H.C., K.-T.S., Y.-C.L., S.-T.H., P.-K.F., B.-J.L., C.-L.L., C.-H.K. Visualization: Y.-W.C., T.-M.Y., C.-H.C., K.-T.S., Y.-C.L., S.-T.H., P.-K.F., B.-J.L., C.-L.L., C.-H.K. Supervision: C.-H.K. Project administration: C.-H.K. Funding acquisition: C.-H.K.

Funding: This work was supported by grants from the Ministry of Health and Welfare, Taiwan (MOHW107-TDU-B-212-123004), China Medical University Hospital (DMR-107-192); Academia Sinica Stroke Biosignature Project (BM10701010021); MOST Clinical Trial Consortium for Stroke (MOST 106-2321-B-039-005-); Tseng-Lien Lin Foundation, Taichung, Taiwan; and Katsuzo and Kiyo Aoshima Memorial Funds, Japan. The funders had no role in study design, data collection and analysis, decision to publish, or preparation of the manuscript. No additional external funding received for this study.

Acknowledgments: This paper/The abstract of this paper was presented at the Europena Renal Conference name ERA-EDTA as a poster presentation/conference talk with interim findings. The poster's abstract was published in "Poster Abstracts" in Nephrology Dialysis Transplantation, Volume 32, Issue suppl_3, 1 May 2017, Pages iii104, https:/ / doi.org/10.1093/ndt/gfx137.SP005.

Conflicts of Interest: All authors report no conflicts of interest.

\section{Abbreviations}

$\begin{array}{ll}\text { PKD } & \text { polycystic kidney disease } \\ \text { ACS } & \text { acute coronary syndrome } \\ \text { CHF } & \text { congestive heart failure } \\ \text { CI } & \text { confidence interval } \\ \text { VSMC } & \text { vascular smooth muscle cells } \\ \text { NHIRD } & \text { National Health Insurance Research Database } \\ \text { ICD-9-CM } & \text { International Classification of Diseases, Ninth Revision, Clinical Modification } \\ \text { HR } & \text { hazard ratio }\end{array}$

\section{References}

1. Kurschat, C.E.; Muller, R.U.; Franke, M.; Maintz, D.; Schermer, B.; Benzing, T. An approach to cystic kidney diseases: The clinician's view. Nat. Rev. Nephrol. 2014, 10, 687-699. [CrossRef] [PubMed] 
2. Torres, V.E.; Harris, P.C.; Pirson, Y. Autosomal dominant polycystic kidney disease. Lancet 2007, 369, 1287-1301. [CrossRef]

3. Bichet, D.; Peters, D.; Patel, A.J.; Delmas, P.; Honore, E. Cardiovascular polycystins: Insights from autosomal dominant polycystic kidney disease and transgenic animal models. Trends Cardiovasc. Med. 2006, 16, $292-298$. [CrossRef] [PubMed]

4. Boulter, C.; Mulroy, S.; Webb, S.; Fleming, S.; Brindle, K.; Sandford, R. Cardiovascular, skeletal, and renal defects in mice with a targeted disruption of the PKD1 gene. Proc. Natl. Acad. Sci. USA 2001, 98, 12174-12179. [CrossRef] [PubMed]

5. Torres, V.E.; Cai, Y.; Chen, X.; Wu, G.Q.; Geng, L.; Cleghorn, K.A.; Johnson, C.M.; Somlo, S. Vascular expression of polycystin-2. J. Am. Soc. Nephrol. 2001, 12, 1-9. [PubMed]

6. Griffin, M.D.; Torres, V.E.; Grande, J.P.; Kumar, R. Vascular expression of polycystin. J. Am. Soc. Nephrol. 1997, 8, 616-626. [PubMed]

7. Kip, S.N.; Hunter, L.W.; Ren, Q.; Harris, P.C.; Somlo, S.; Torres, V.E.; Sieck, G.C.; Qian, Q. [Ca $\left.{ }^{2+}\right]$ i reduction increases cellular proliferation and apoptosis in vascular smooth muscle cells: Relevance to the ADPKD phenotype. Circ. Res. 2005, 96, 873-880. [CrossRef] [PubMed]

8. Marx, S.O.; Jayaraman, T.; Go, L.O.; Marks, A.R. Rapamycin-FKBP inhibits cell cycle regulators of proliferation in vascular smooth muscle cells. Circ. Res. 1995, 76, 412-417. [CrossRef] [PubMed]

9. Martin, K.A.; Rzucidlo, E.M.; Merenick, B.L.; Fingar, D.C.; Brown, D.J.; Wagner, R.J.; Powell, R.J. The mTOR/p70 S6K1 pathway regulates vascular smooth muscle cell differentiation. Am. J. Physiol. Cell Physiol. 2004, 286, C507-C517. [CrossRef] [PubMed]

10. Morice, M.C.; Serruys, P.W.; Sousa, J.E.; Fajadet, J.; Ban Hayashi, E.; Perin, M.; Colombo, A.; Schuler, G.; Barragan, P.; Guagliumi, G.; et al. A randomized comparison of a sirolimus-eluting stent with a standard stent for coronary revascularization. N. Engl. J. Med. 2002, 346, 1773-1780. [CrossRef] [PubMed]

11. Gallo, R.; Padurean, A.; Jayaraman, T.; Marx, S.; Roque, M.; Adelman, S.; Chesebro, J.; Fallon, J.; Fuster, V.; Marks, A.; et al. Inhibition of intimal thickening after balloon angioplasty in porcine coronary arteries by targeting regulators of the cell cycle. Circulation 1999, 99, 2164-2170. [CrossRef] [PubMed]

12. Harris, P.C.; Torres, V.E. Genetic mechanisms and signaling pathways in autosomal dominant polycystic kidney disease. J. Clin. Investig. 2014, 124, 2315-2324. [CrossRef] [PubMed]

13. Lieberthal, W.; Levine, J.S. The role of the mammalian target of rapamycin (mTOR) in renal disease. J. Am. Soc. Nephrol. 2009, 20, 2493-2502. [CrossRef] [PubMed]

14. Tao, Y.; Kim, J.; Schrier, R.W.; Edelstein, C.L. Rapamycin markedly slows disease progression in a rat model of polycystic kidney disease. J. Am. Soc. Nephrol. 2005, 16, 46-51. [CrossRef] [PubMed]

15. Shillingford, J.M.; Murcia, N.S.; Larson, C.H.; Low, S.H.; Hedgepeth, R.; Brown, N.; Flask, C.A.; Novick, A.C.; Goldfarb, D.A.; Kramer-Zucker, A.; et al. The mTOR pathway is regulated by polycystin-1, and its inhibition reverses renal cystogenesis in polycystic kidney disease. Proc. Natl. Acad. Sci. USA 2006, 103, 5466-5471. [CrossRef] [PubMed]

16. Yu, T.M.; Chuang, Y.W.; Yu, M.C.; Huang, S.T.; Chou, C.Y.; Lin, C.L.; Chiu, C.C.; Kao, C.H. New-onset Atrial Fibrillation is Associated With Polycystic Kidney Disease: A Nationwide Population-based Cohort Study. Medicine (Baltimore) 2016, 95, e2623. [CrossRef] [PubMed]

17. Irazabal, M.V.; Huston, J., 3rd; Kubly, V.; Rossetti, S.; Sundsbak, J.L.; Hogan, M.C.; Harris, P.C.; Brown, R.D., Jr.; Torres, V.E. Extended follow-up of unruptured intracranial aneurysms detected by presymptomatic screening in patients with autosomal dominant polycystic kidney disease. Clin. J. Am. Soc. Nephrol. 2011, 6, 1274-1285. [CrossRef] [PubMed]

18. Fick, G.M.; Johnson, A.M.; Hammond, W.S.; Gabow, P.A. Causes of death in autosomal dominant polycystic kidney disease. J. Am. Soc. Nephrol. 1995, 5, 2048-2056. [PubMed]

19. Ecder, T.; Schrier, R.W. Cardiovascular abnormalities in autosomal-dominant polycystic kidney disease. Nat. Rev. Nephrol. 2009, 5, 221-228. [CrossRef] [PubMed]

20. Fine, J.P.; Gray, R.J. A proportional hazards model for the subdistribution of a competing risk. J. Am. Stat. Assoc. 1999, 94, 496-509. [CrossRef]

21. Ecder, T.; Schrier, R.W. Hypertension in autosomal-dominant polycystic kidney disease: Early occurrence and unique aspects. J. Am. Soc. Nephrol. 2001, 12, 194-200. [PubMed] 
22. Alfonso, F.; Paulo, M.; Gonzalo, N.; Dutary, J.; Jimenez-Quevedo, P.; Lennie, V.; Escaned, J.; Bañuelos, C.; Hernandez, R.; Macaya, C. Diagnosis of spontaneous coronary artery dissection by optical coherence tomography. J. Am. Coll. Cardiol. 2012, 59, 1073-1079. [CrossRef] [PubMed]

23. Hadimeri, H.; Lamm, C.; Nyberg, G. Coronary aneurysms in patients with autosomal dominant polycystic kidney disease. J. Am. Soc. Nephrol. 1998, 9, 837-841. [PubMed]

24. Itty, C.T.; Farshid, A.; Talaulikar, G. Spontaneous coronary artery dissection in a woman with polycystic kidney disease. Am. J. Kidney Dis. 2009, 53, 518-521. [CrossRef] [PubMed]

25. Magadle, R.; Weiner, P.; Rabner, M.; Mizrahi-Reuveni, M.; Davidovich, A. Polycystic kidney disease as a new risk factor for coronary events. Isr. Med. Assoc. J. 2002, 4, 21-23. [PubMed]

26. Qian, Q.; Li, M.; Cai, Y.; Ward, C.J.; Somlo, S.; Harris, P.C.; Torres, V.E. Analysis of the polycystins in aortic vascular smooth muscle cells. J. Am. Soc. Nephrol. 2003, 14, 2280-2287. [CrossRef] [PubMed]

27. Wu, G.; Markowitz, G.S.; Li, L.; D’Agati, V.D.; Factor, S.M.; Geng, L.; Tibara, S.; Tuchman, J.; Cai, Y.; Park, J.H.; et al. Cardiac defects and renal failure in mice with targeted mutations in PKD2. Nat. Genet. 2000, 24, 75-78. [CrossRef] [PubMed]

28. Yu, T.M.; Lin, C.L.; Chang, S.N.; Sung, F.C.; Kao, C.H. Increased risk of stroke in patients with chronic kidney disease after recurrent hypoglycemia. Neurology 2014, 83, 686-694. [CrossRef] [PubMed]

29. Vrints, C.J. Spontaneous coronary artery dissection. Heart 2010, 96, 801-808. [CrossRef] [PubMed]

30. Mortensen, K.H.; Thuesen, L.; Kristensen, I.B.; Christiansen, E.H. Spontaneous coronary artery dissection: A Western Denmark Heart Registry study. Catheter. Cardiovasc. Interv. 2009, 74, 710-717. [CrossRef] [PubMed]

(C) 2018 by the authors. Licensee MDPI, Basel, Switzerland. This article is an open access article distributed under the terms and conditions of the Creative Commons Attribution (CC BY) license (http:/ / creativecommons.org/licenses/by/4.0/). 